\title{
The Study of the Green Marketing and Sustainable Development
}

\author{
Hai-Jin Ji ${ }^{\mathrm{a}}$, Shao-Hua Liu \\ School of Management of Yangtze University Jingzhou, Hubei, 434023, China \\ ajhqlsh@126.com, ${ }^{b}$ Ish811@126.com
}

Keywords: Sustainable development, Green marketing, Strategy.

\begin{abstract}
With the development of modern industry and the prosperity society, our living environment has been getting worse. And people have to rethink about their actions. In order to make the sustainable development come true in the harmonious environment, society put higher requirement about the enterprise production and the green marketing. First, this paper introduces the connotation of the green marketing and the sustainable development. Then, that clarifies the relationship of the green marketing and the sustainable development. Finally, that puts forward the strategies in order to realize social sustainable development and green marketing.
\end{abstract}

\section{Introduction}

Social productivity develop rapidly and promote the social development of human being in the 20th centuries. But there are some negative effects arising with the economic development: First, the population explosion, the excessive exploitation and consumption of natural resources, the exhaust emissions of three wastes and so on. All of these have brought unprecedented challenges to mankind. Second, most companies ignore the green marketing and do not realize that it is important to the consumers, enterprises and society. Such as poison gas, poor quality garments, Sudan red salted egg, fried twisted stick cooked by illegal cooking oil, catalyzed tomatoes, whitening agent steamed bread etc. All of these not only harm the physical and psychological health of consumers, but also not good for the sustainable development of company. In the face of the plight of this kind of "growth without long-term development", the sustainable development strategy has been put forward in 1980s. At the same time, it was accepted by various countries. Also, green marketing which is the important way for enterprises to carry out the strategy of sustainable development, and it will become the mainstream of marketing in the 21 st century.

\section{The Connotation of Green Marketing and Sustainable Development}

Professor Ken Peattic who is from Swansea College shows the ideas in his book Green Marketing - A Trend Crisis for the Business Management that Green marketing is a kind of business management process which can identify, expect, and meet the demand of consumption society, and it can be profitable and sustainable. Traditional marketing research focus is a "magic triangle" composed of enterprises, customers and competitors, and the main way to gain profit is to coordinate the relationship among enterprises, customers and competitors. However during the production and management, the green marketing emphasize that enterprise should put their own interests, consumer interests and long-term interests of the society together which will be the central idea for company to concept, design, sale and manufacture their product and service. Therefore, green marketing pay more attention to the global environmental problems and social sustainable development problems, and can be regarded as a deep extension of the traditional marketing, and will be more meaningful than traditional marketing.

Sustainable development refers to not only meet the needs of contemporary, does not damage the ability of future generations to meet need development. Sustainable development should achieve the goal of economic development. Also sustainable development ask us to protect natural resources and environmental, such as: the atmosphere, fresh water, sea, land and forests, etc. So future generations can achieve sustainable development and live and work in peace and contentment. From 1987, world commission on environment and development (WCED), which is led by Mrs Boulogne, published a 
report Our Common Future. This report formally use the concept of sustainable development. In March 1994, the State Council issued China's Agenda 21 -- White Paper on China in the 21st Century, Population, Environment and Development and put forward the overall strategy, countermeasures and action plan for China to implement the sustainable development. Thus it can be seen that our country has been paying equal attention to explore the ecological environment and economic sustainable development strategy referred to the agenda of the 21 st century.

\section{The Relationship between Green Marketing and Sustainable Development}

The relationship between green marketing and sustainable development can be summarized as following: first, sustainable development promotes the formation and development of green marketing; second, the implementation of green marketing benefits the sustainable development of the enterprises and the society [2].

\section{Green Marketing Benefits the Sustainable Development of the Enterprises and the Society.}

Green Marketing Can Improve the Competitive Edge for Enterprises. With the popularity of green consuming idea, no only will the consumers put emphasis on the quality or the price, they focus on natural, environmental and healthy issues which gradually become fashion consumption. It will definitely increase the competitive power of enterprises in market if the enterprises carry out green marketing and develop green production.

Green Marketing Helps the Enterprises Reduce Cost and Gain More Profits. Green marketing requires that the enterprises avoid excessive packaging, and use the recycled packaging, adopting circular economy pattern to achieve efficient use of resources and reduction of cost.

Green Marketing Helps Establish Fair Corporate Culture. The fact that enterprises carry out the green marketing on the base of environment protection and pursuit of fairness and harmony helps inspire the staff to identify with the spiritual culture, strengthen cohesive forces of the enterprises and establish fair corporate culture.

\section{Sustainable Development Requires Companies to Take Green Marketing Strategies}

(1) Sustainable development promotes companies to take environment harmony production mode, and then promotes the beginning of green marketing.

At present, the production of companies will not only concentrate on the increase of their outputs but also should pay much attention to on how to cut down the pollution and protect the environment. The theory of green marketing holds the opinion that the production of modern society is to create material goods by remaking nature reasonable and under the premise of protect nature resource and environment. It requires that the production should be carried out within an affordable range of nature resource and develop new resources, new technology and use green technology, do not pollute the environment or damage the ecological during the production process.

Sustainable development encourages consumers to make green consumption, thus promoting the development of green marketing. Green consumption is from the point of meeting the ecological needs, promoting healthy body and protecting ecological environment as the basic connotation. It's the collective name of a variety of consumer behaviors and consumption patterns that meet the standards of good for people's health and environmental harmony. The content of green consumption is very broad, including not only green products but also the recycle and reuse of materials, effective use of energy and the protection of living environment and species. The sustainable development of enterprises and society related to each of us. Advocating green consumption is also our personal responsibility and obligation.

\section{The Implementing Green Marketing Strategies in Order to Achieve Sustainable Development}

\section{Consumers Should Establish the Awareness of Green Consumption and Promote the Implementation of Green Marketing}

What people think plays a guiding role in what to buy. For one thing, consumers, as the main role of green products consumption, have come to understand the seriousness of the problem and the relevant 
regulatory environment, and enhanced the environmental friendly awareness, and promoted the implementation of green marketing after being exposed to knowledge of environmental protection; for another, with the improvement of people's living standard, people are inclined to consider their own physical and mental health, and prefer green consumption. Awakening and strengthening of civic consciousness is basic and fundament of green marketing, which determines the size of the market demand for green products. At the same time, it can create a strong pressure of public opinion to influence government and corporate responsibility for ecological environment. Each of us is a member of society, we must strive to improve our green consumer awareness, and influence the people around us. Ultimately, we reach the goal that we make green consumption, green products, green marketing as the mainstream of consumption, achieving sustainable development of society.

\section{The Enterprise Should Make the Green Marketing from the Marketing Mix Strategy}

(1) Develop green products. Developing green products is the key to enterprises to implement green marketing. Developing green products include product design, material selection, function and structure of product, manufacturing process, packaging and transportation, product ' s service and the processing of waste products. All of those should consider the effect to the ecological environment. As for product design, taking full advantages of resource and energy and protecting ecological environment should be emphasized. Also, it is important to reduce the using of non renewable resources as we can and design low or no pollution and no harm to human health products which save raw materials and energy and is recyclable; Then we should pay attention to "clean production" which means we should avoid the using of harmful toxic raw materials and intermediate products as far as possible and apply to technology and efficient equipment with no waste or less waste; As for product packaging, we should select biodegradable non-toxic materials and make packing material simplification, standardization and avoid excessive packaging; After-sales service should consider how to deal with the waste In order to avoid the environmental pollution and adverse effects [1].

(2)Make green price. The green price is a new concept of marketing strategy which means that enterprise should set concept which include "polluters pay principle", "paying for the using of environment" and "using resource in economic way". Green price consist of green cost which is the cost that the enterprise had paid to protect environment. Price of green in the field of environmental protection investment is in view of the natural and ecological environment in the process of human use of value compensation [4]. According to statistics, Japan's green food price is about $20 \%$ higher than that of common food; Finnish government allowed its price is $30 \%$ higher than that of general food prices above, Germany's ecological food price is $50 \%$ higher than common food about $200 \%$. As businesses, green price formulation will weaken the competitiveness of the enterprises. However, green prices reflect the environment and resources, even if the enterprise do not implement green price, with the standard of environmental law and strengthen, from a long-term perspective, the production cost of enterprises will continue to increase [3].

(3) Develop green channel. According to the characteristics of the green products, we can carefully select agents, wholesalers, retailers which have credibility and good public image, concern about the environment, devote to public-spirited services and identify with the green products. Also we can promote green products by taking advantages of resellers' selling network. We should pay attention to the overall process in order to reduce pollution, such as raw material supply, products production, selling and consumption. And that can prevent the secondary pollution in the process of green product in distribution. Enterprises should be under the guidance of the concept of green, choose pollution-free transportation and implement green logistics. At the same time, we can reduce waste in the process of storage and transportation and resource consumption by using the city distribution center, logistics base and so on to set up reasonable supply and distribution[3].

(4) Green Promotion. Green marketing ask enterprises to emphasize environmental awareness in the marketing mix, such as: advertisement, public relation, sales promotion etc. Also promoting 
environmental protection concept can not only establish enterprise image, but also can stimulate consumers to buy and use green products.

\section{Government Should Strengthen Guidance and Promote Green Marketing Activities}

Chinese enterprises' green marketing is a systematic project, in which the government plays an important role as macro-controller. In the process of green marketing, the government should do the following:

(1)Change the traditional concept of natural resources and foster green awareness

In conventional wisdom, it's believed that the natural resources required for human beings is inexhaustible. But the worsening global environment impose real threat to human survival and development. Therefore, the government should guide and stimulate consumers to purchase environmentally friendly products, improve enterprise's and people's environmental awareness and risk prevention abilities, cultivate green values of production and consumption, thus consciously maintain and create a green society and green environment. As soon as possible cultivate green consciousness of our nation.

(2)Strengthen government supervision

Although China has established market economy system, government intervention in the market continues to weaken, but at present, the market mechanism is not perfect, we must rely on the power of government to reasonably solve the environmental impact of rapid economic growth and put limitations on polluting enterprises' development.

(3)Strengthen macro-control, establish positive interaction mechanism

Government, enterprises, consumers, as the three forces of the implementation of for green marketing and sustainable development, establish a joint management mechanism in which they three can give full play to their respective roles. The Government should give full play to the macro-control functions to foster Green Marketing, write environmental protection into national economic and social development planning, and improve the policy system such as legislation, the establishment of regulatory agencies, guaranteed investment strategy to achieve this goal.

In short, in order to achieve sustainable development of society, to carry out green marketing is an inevitable requirement and concrete manifestation of enterprises; Green Marketing is also a need to enhance the vitality of enterprises and activities, it is also the realization of a sustainable society demands.

\section{Acknowledgements}

This work was financially supported by the Young teachers in colleges and universities in Hubei province in-depth enterprise action plan project (XD2014087), also supported by the Yangtze university social science fund research project for 2013.

\section{References}

[1] X.X. MIN: Discussion of Green Marketing and Sustainable Development[J], Wuhan University, 1998, (6): 52-59.

[2] X.Z. MENG: research of Green Marketing Performance Evaluation Based on Sustainable Development[D] Tianjin University of Finance and Economics, 2009.

[3] Y. CUI:Relationship between Green Marketing and Sustainable Development [J], Coastal Enterprises and Science \& Technology, 2005, (12), 5-7.

[4] R.G. Zhang: environmentally sustainable development of China's enterprises under green marketing research [D], Liaoning Technical University., 2004. 